\title{
State legislators' perceptions of lobbyists and lobbying on tobacco control issues
}

Joanna E Cohen, Adam O Goldstein, Brian S Flynn, Michael C Munger, Nell H Gottlieb, Laura J Solomon, Greg S Dana

\begin{abstract}
Objective-To determine state legislators' perceptions about health and tobacco lobbyists, their frequency of contact with these lobbyists, and the amount of campaign contributions from health professional organisations and the tobacco industry.

Design-Cross-sectional study.

Subjects-State legislators from North Carolina, Texas, and Vermont (USA), serving in 1994.
\end{abstract}

Main outcome measures-Perceptions about lobbyists representing the tobacco industry, non-profit health organisations, and state medical societies with respect to their credibility, importance as sources of information, and persuasiveness; extent of lobbying activities; campaign contributions from health professional organisations and the tobacco industry.

Results-Almost all legislators reported that medical society and non-profit health organisation lobbyists are credible on tobacco issues and just over half believed that these lobbyists are important sources of information. More legislators said they could be persuaded by medical and health lobbyists than by tobacco lobbyists. Although health professional Political Action Committees (PACs) gave campaign contributions to more state legislators, and gave higher amounts on average, than tobacco PACs, legislators reported less contact with medical society lobbyists than tobacco lobbyists about tobacco issues.

Conclusions-State legislators have positive attitudes toward lobbyists for non-profit health organisations and state medical societies regarding tobacco issues. These groups may be an underused resource for educating legislators about tobacco control measures.

(Tobacco Control 1997;6:332-336)

Keywords: lobbying, tobacco control, legislators

\section{Introduction}

Tobacco-related diseases continue to be the number one cause of preventable death in the United States. ${ }^{1}$ Increasingly, legislative measures are seen as critical components of a comprehensive strategy to reduce tobacco consumption. ${ }^{2}$ As a result, there is a growing interest in understanding the factors that influence the passage of tobacco-related regulations. ${ }^{3}$
Lobbying activities and campaign contributions are two factors that can affect legislators' voting behaviour. ${ }^{45}$ Lobbyists can influence legislators by providing information that convinces them, and helps them convince others, that they should support (or oppose) proposed legislation; lobbyists can also exert an influence by organising a legislator's constituency to lobby their representative. ${ }^{6}$ Campaign contributions may influence legislative outcomes by financially supporting candidates who are most sympathetic to the contributor's policy goals. Contributions can also buy access for lobbyists or can amplify lobbyists' messages to influence the behaviour of legislators once they are elected. ${ }^{7}$

Existing studies suggest that lobbying activities $^{910}$ and campaign contributions ${ }^{1112}$ influence legislators' positions on tobaccorelated measures. There is no research, however, that delineates how legislators view lobbyists for non-profit health, medical, and tobacco organisations, or the amount of contact between lobbyists and legislators on tobacco issues.

The objectives of this research were to describe: (a) state legislators' perceptions about health, medical, and tobacco lobbyists with respect to their credibility, importance as sources of information on tobacco issues, and ability to persuade; (b) the level of campaign contributions to state legislators from health professional organisations and the tobacco industry; and, (c) state legislators' reported frequency of contact with lobbyists and evaluation of the amount of contact.

\section{Methods}

The State Legislator Study has been described previously. ${ }^{13}$ During the summer of 1994 , state legislators in North Carolina (NC), Texas (TX), and Vermont (VT) (USA) were interviewed about their knowledge, attitudes, and intentions to vote on various tobacco control issues. These three states were chosen because they represented a range of legislative activity with respect to tobacco control and a range of economic dependence on tobacco. During the 1993-94 legislative session, the TX legislature did not vote on any tobacco-related bills. In 1993, the NC legislature passed a clean indoor air bill which pre-empted local communities from passing stronger legislation. The NC house also passed a weak tobacco sales to minors bill the same year. The VT legislature passed strong clean indoor air legislation in 1993. 
Overall, $84 \%$ of state legislators completed structured interviews: 145 in NC (86\%), 129 in TX $(71 \%)$, and 170 in VT $(95 \%)$. More than $88 \%$ of interviews occurred face to face; the remainder were conducted over the telephone. Legislators were assured both verbally and in written form that their responses would remain confidential. $\mathrm{Re}$ spondents tended to be older with lower levels of legislative experience and status. Among survey participants, $87 \%$ ran for re-election, and of these $88 \%$ won their re-election campaign.

Legislators were asked several questions about lobbyists representing the tobacco industry, non-profit health organisations, and state medical societies. To measure perceptions of credibility, legislators were asked: "How credible are representatives of [each of the three categories of organisations] when discussing tobacco-related issues with you?", with possible responses being "very credible", "somewhat credible", "not very credible", or "not credible at all". To measure importance as a source of information, legislators were asked: "How important would you say that lobbyists for [each category] are as a source of information on tobacco issues?", with the response scale anchored by "very important" (1) and "not important at all" (5). To measure the persuasiveness of each category of lobbyist, legislators were asked "How likely or unlikely is it that you would be persuaded by the opinions of lobbyists for [each category] when voting on tobacco legislation?"; the response scale was anchored by "very likely" (1) and "very unlikely" (5).

Data on 1993-94 campaign contributions to legislators were obtained from the appropriate state office-for example, the State Board of Elections or the Ethics Commission-and included the following Political Action Committees (PACs): the state medical society, the state dental society, RJ Reynolds, and Philip Morris. The North Carolina Farm Bureau was also included in NC. Organisations such as the Tobacco Institute and the non-profit health organisations were not registered to donate funds to candidates for positions in these state legislatures. Contributions from medical and dental society PACs were combined to represent "health profes- sional" interests; contributions from the remaining PACs were combined to represent pro-tobacco interests.

To measure frequency of cogtact with lobbyists, legislators were asked for number of times in the previous two years that they had had face-to-face contact with lobby resentatives from each of the three cogtegories of organisations, about tobacco-relafed issues. Legislators also provided an evaluation of the amount of contact they had with tobacco and non-profit lobbyists by indicating wbether they had "too much", "about the right amount", or "too little" contact with these lobbyists about tobacco-related issues.

Stata $^{14}$ was used to calculate ${ }_{\text {eld }}$ ratios (ORs), 95\% confidence intervals (C. $\overrightarrow{\mathrm{PS}}$ ) for proportions, and conservative $95 \%$ CIs for percentiles which prevent interpolgtion when estimating the distribution-free Nonfidence limits.

\section{Results}

In 1993-94, there were 13 register@d tobacco lobbyists in NC, seven in TX, and 14 in VT. During the same period, there there registered non-profit health lobbyists in NC, three in TX, and six in VT. NC had five registered medical society lobbyists, Ty had 16 , and VT had three. ${ }^{15}$

\section{PERCEPTIONS ABOUT LOBBYISTS}

More than $90 \%$ of state legislators 옹 all three states said that lobbyists for the pon-profit health organisations and for tho medical society were "somewhat credible" or "very credible" (table 1). In each state, đegislators rated medical society lobbyists ingher in credibility than tobacco lobbyists. FI TX and VT, non-profit health lobbyists alsø received higher credibility ratings than tobacco lobbyists. Although there was substahtial variation among states in the reported crEdibility of tobacco lobbyists, at least half of le gislators in each state responded that tobacc $\$$.lobbyists were credible.

Overall, just over half of the legisłators said that medical society lobbyists $(56 \% ; 95 \% \mathrm{CI}=$ $51 \%$ to $61 \%$ ) and non-profit healtb lobbyists $(52 \% ; 95 \% \mathrm{CI}=48 \%$ to $57 \%)$ were tant" or "very important" source of information on tobacco-related issues, compared with $29 \%$

Table 1 State legislators'perceptions about lobbyists

\begin{tabular}{|c|c|c|c|c|c|c|}
\hline & \multicolumn{2}{|r|}{ NC } & \multicolumn{2}{|r|}{$T X$} & \multicolumn{2}{|r|}{$\underset{\sim}{V} V T$} \\
\hline & (\%) & $95 \% C I$ & $(\%)$ & $95 \% C I$ & $(\%)$ & D्ले5\% CI \\
\hline \multicolumn{6}{|c|}{ Proportion of legislators reporting that lobbyists are very or somewhat credible regarding tobacco issues } & \\
\hline Tobacco lobbyists & 86 & $81-92$ & 68 & $58-78$ & 53 & वै4-61 \\
\hline Non-profit health lobbyists & 93 & $89-98$ & 93 & $88-98$ & 92 & Фా8-97 \\
\hline Medical society lobbyists & 96 & $93-100$ & 98 & $95-100$ & 96 & 993-99 \\
\hline \multicolumn{7}{|c|}{ Proportion of legislators reporting that lobbyists are an important or very important source of information about tob } \\
\hline Tobacco lobbyists & 42 & $34-50$ & 26 & $18-33$ & 19 & $13-25$ \\
\hline Non-profit health lobbyists & 50 & $42-58$ & 55 & $46-64$ & 52 & $<4-59$ \\
\hline Medical society lobbyists & 56 & $48-64$ & 65 & $57-73$ & 49 & 21-57 \\
\hline \multicolumn{6}{|c|}{ Proportion of legislators reporting that they are likely or very likely to be persuaded by lobbyists } & \\
\hline Tobacco lobbyists & 16 & $10-22$ & 12 & $7-18$ & 4 & $\lesseqgtr 1-6$ \\
\hline Non-profit health lobbyists & 25 & $18-32$ & 39 & $30-48$ & 33 & बें6-40 \\
\hline Medical society lobbyists & 36 & $29-44$ & 50 & $42-59$ & 36 & Ђ्ञ8-43 \\
\hline
\end{tabular}

NC $=$ North Carolina; TX $=$ Texas VT $=$ Vermont

For the questions on credibility, numbers ranged from 116 to 134 in NC, from 88 to 101 in TX, and from 154 to 164 in VT. For the other two sets of questions, numbers were as follows: 145 in NC, 128 to 129 in TX, and 169 to 170 in VT.

$\mathrm{CI}=$ confidence intervals. 
Table 2 State legislators' contact with lobbyists about tobacco-related issues

\begin{tabular}{|c|c|c|c|c|c|c|}
\hline & \multicolumn{2}{|r|}{$N C$} & \multicolumn{2}{|c|}{$T X$} & \multicolumn{2}{|c|}{$V T$} \\
\hline & $(\%)$ & $95 \% C I$ & $(\%)$ & $95 \% C I$ & $(\%)$ & $95 \% C I$ \\
\hline \multicolumn{7}{|c|}{ Proportion of legislators with at least one face-to-face contact in the past two years with: } \\
\hline Tobacco lobbyists & 84 & $78-90$ & 50 & $41-59$ & 77 & $70-83$ \\
\hline Non-profit health lobbyists & 66 & $58-74$ & 64 & $56-73$ & 82 & $76-87$ \\
\hline Medical society lobbyists & 56 & $48-64$ & 54 & $45-63$ & 64 & $56-71$ \\
\hline Constituents supportive of tobacco control & 59 & $51-67$ & 64 & $55-72$ & 74 & $67-80$ \\
\hline Pro-tobacco constituents & 67 & $59-75$ & 60 & $52-69$ & 76 & $69-82$ \\
\hline Tobacco farmers & 67 & $59-75$ & NA & & NA & \\
\hline \multicolumn{7}{|c|}{ Median number of face-to-face contacts in the past two years, if legislator had at least one contact: } \\
\hline Tobacco lobbyists & 5 & $3-6$ & 2 & $2-3$ & 8 & $5-10$ \\
\hline Non-profit health lobbyists & 4 & $3-5$ & 4 & $3-5$ & 10 & $6-10$ \\
\hline Medical society lobbyists & 2 & $2-3$ & 3 & $2-5$ & 4 & $3-5$ \\
\hline Constituents supportive of tobacco control & 4 & $3-5$ & 5 & 3-6 & 6 & $5-10$ \\
\hline Pro-tobacco constituents & 5 & $4-10$ & 4 & $3-5$ & 5 & $4-6$ \\
\hline Tobacco farmers & 7 & $5-12$ & NA & & NA & \\
\hline
\end{tabular}

(95\% CI $=24 \%$ to $33 \%$ ) for tobacco lobbyists. In TX and VT, medical society lobbyists and non-profit health lobbyists received higher ratings than tobacco lobbyists as important sources of information (table 1 ). Tobacco lobbyists were a more important source of information in NC than in TX or VT.

Although a minority of legislators said that they were "likely" or "very likely" to be persuaded by any of the three groups of lobbyists, significant differences existed among groups (table 1). Overall, three to four times more legislators said that they could be persuaded on tobacco issues by non-profit health $(32 \% ; 95 \% \mathrm{CI}=28 \%$ to $36 \%)$ and medical society ( $40 \% ; 95 \% \mathrm{CI}=36 \%$ to $45 \%$ ) lobbyists than by tobacco lobbyists $(10 \% ; 95 \%$ $\mathrm{CI}=7 \%$ to $13 \%$ ). In each state, legislators who said the group of lobbyists was an important source of information on tobacco issues were more likely to report that they could be persuaded by non-profit health lobbyists $(\mathrm{OR}=6.85 ; 95 \% \mathrm{CI}=4.25$ to 11.04$)$ and medical society lobbyists $(\mathrm{OR}=7.36 ; 95 \%$ $\mathrm{CI}=4.67$ to 11.59 ).

\section{CAMPAIGN CONTRIBUTIONS FROM TOBACCO AND} HEALTH SOURCES

In 1993-94, the proportion of legislators receiving contributions from tobacco PACs was $38 \%$ in NC and $12 \%$ in $\mathrm{TX}$; the proportion of legislators receiving contributions from health professional PACs was $86 \%$ in NC and $87 \%$ in TX. In NC, the median size of a tobacco PAC contribution ( $\$ 500$; range $\$ 100-\$ 2200$ ) was lower than the median contribution by health professional PACs $(\$ 650$; range $\$ 100-\$ 3000$ ). In $\mathrm{TX}$, the median levels were the same $(\$ 1000)$ for tobacco (range $\$ 500-\$ 2000$ ) and health (range \$195-\$24250) PACs. In keeping with the relative absence of interest group contributions in VT state legislator campaigns during the period investigated, only one VT state legislator received any money from a tobacco PAC and only four received money from a health professional PAC.
CONTACT WITH LOBBYISTS ABOUT

TOBACCO-RELATED ISSUES

Legislators were asked about the amount of face-to-face contact they had with lobbyists about tobacco-related issues, during the 1993-94 legislative session (table 2). Overall, $\mathbb{\Phi}$ fewer legislators reported any face-to-face contact with medical society lobbyists $(58 \%$; $95 \% \mathrm{CI}=54 \%$ to $63 \%$ ) compared with non-profit health lobbyists (72\%; 95\% CI = $67 \%$ to $76 \%$ ) and tobacco lobbyists $(72 \%$; $95 \% \mathrm{CI}=67 \%$ to $76 \%$ ). In each state, there were no statistically significant differences in the proportion of legislators who had at least one face-to-face contact with constituents who were supportive of tobacco control ( $66 \%$ overall; $95 \% \mathrm{CI}=62 \%$ to $71 \%$ ) and the proportion of legislators who had at least one contact with constituents who were pro-tobacco $(68 \%$ overall; $95 \% \mathrm{CI}=64 \%$ to $73 \%)$. Sixty-seven per cent of NC legislators reported having at least one meeting with tobacco farmers about tobacco-related issues.

Of those legislators who had face-to-face contact with lobbyists on tobacco-related issues, the median number of visits varied among groups and among states (table 2). 오 Overall, the median number of reported visits $\frac{D}{0}$ from medical society lobbyists $(3 ; 95 \% \mathrm{CI}=2$ to 4 ) was less than that from non-profit health $N$ lobbyists $(5 ; 95 \% \mathrm{CI}=5$ to 6$)$ and tobacco $N$ lobbyists $(5 ; 95 \% \mathrm{CI}=5$ to 5$)$. VT legislators N reported the most visits by each group of $O$ lobbyist, with 10 from non-profit health organisations, eight from the tobacco industry, and four from the medical society; these $\stackrel{\oplus}{+}$ relatively high numbers of contacts are likely a 7 result of the Vermont legislature's consideration of strong clean indoor air legislation in 1993. ${ }^{16}$

When asked to evaluate the amount of contact with lobbyists on tobacco-related issues, $\delta$ most legislators in each state said that they had about the right amount of contact with tobacco and non-profit health lobbyists. However, a substantial percentage of legislators in NC $(32 \% ; 95 \% \mathrm{CI}=24 \%$ to $40 \%)$ and $\mathrm{TX}(35 \%$; $95 \% \mathrm{CI}=27 \%$ to $44 \%$ ) said that they had too 
little contact with non-profit health lobbyists, and, overall, more than twice as many legislators stated that they had too little contact with non-profit health lobbyists $(26 \% ; 95 \%$ $\mathrm{CI}=22 \%$ to $30 \%)$ compared with tobacco lobbyists $(11 \% ; 95 \% \mathrm{CI}=8 \%$ to $14 \%)$. (This series of questions was not asked about lobbyists for the medical society.)

\section{Discussion}

This research is the first to document quantitatively state legislators' attitudes and opinions regarding lobbying activities that pertain to tobacco-related legislation; our data also provide unique information on the extent of lobbying in the state legislative arena. Although medical society and non-profit health lobbyists received high ratings for credibility and importance as a source of information on tobacco issues, medical society lobbyists had the least amount of reported contact with state legislators about tobacco issues. However, the state medical and dental societies gave campaign contributions to more legislators than did the tobacco industry, and the health professional contributions to legislators were higher, on average, than those of the tobacco industry. These data suggest that, despite public policy statements and recommendations for tobacco control at the national level, ${ }^{17}{ }^{18}$ state medical societies may not be devoting adequate lobbying resources or commitment to tobacco policy measures.

Clearly, medical societies have a diverse legislative agenda, and they may be unlikely to make tobacco control a priority unless solicited to do so by their members. Tobacco control advocates should explore ways of mobilising physicians to generate these directives, while at the same time acknowledging that the interests of medical societies may sometimes conflict with the interests of non-profit health groups on tobacco control issues. However, medical societies may benefit by devoting more resources to a public health issue that is not seen as self-serving; indeed, it has been reported that medical societies can strengthen their ability to gain legislative support for issues related to medical economics and physician practice by actively supporting public health measures. ${ }^{10}$

It is not surprising that tobacco industry lobbyists were given relatively high levels of credibility by many legislators. Lobbyists for the tobacco industry tend to be employed by a greater number of organisations than are health lobbyists, most are fulltime compared with those who lobby only part-time for many voluntary health organisations, and many even lobby for health-related organisations. ${ }^{15}$ Our research did not explore the effects of the age, gender, educational level, or prestige of lobbyists, but these factors may also influence legislators' relationships with lobbyists.

Although there were only three study states, they were diverse in terms of geographical region and approaches to tobacco control, and the findings complement results from studies that used different research methods to examine similar issues. ${ }^{910}$ One concern is that our

study examined tobacco control lobbying in terms of legislators' perceptions blut not in terms of the effect the lobbyists had on actual voting behaviour. It could be argue of for example, that legislators who expressed a receptivity to increased contact with healthi lobbyists would vote for tobacco control legis和ion even without being contacted by these lobbyists. However, evidence in the politiol science literature supports the importance of lobbying activities on actual votes. ${ }^{48}$ Althou $\overline{6}$ host of the data presented above are foased on self-reports and thus could be influenced by social desirability considerations, $\overrightarrow{\vec{e}}$ found a strong relationship between legislatërs' survey responses regarding their voting intemtions and subsequent voting behaviour, in the $\vec{e}$ one state where this comparison was possible 0 9

In view of our findings, additionial research should examine possible barriers tojand methods for, increased lobbying on tobaeco control issues by medical societies and health organisations. The effectiveness different types of lobbying strategies, and their appropriateness for different types of tobacco control legislation being considerêd, should also be examined. More data on the relationships between lobbying aeqivities on tobacco issues and legislative outgomes are important, but lack thereof should got prevent medical societies and non-profit he from taking a more active role in labbying for tobacco control measures.

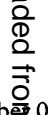

This research project was funded by grant numb 영 022933 from the Robert Wood Johnson Foundation. JC was also funded through a traineeship from the Center for Health Promotion and Disease Prevention, University of North Carelina at Chapel Hill.

1 US Department of Health and Human Servises. Preventing tobacco use among young people. A report of th Surgeon General, 1994. Atlanta, Georgia: Public Health Service, Centers for Disease Control and Prevention, Offee on Smoking and Health, 1994 (US Government Printing Office No and Health, 1994 (US Government Printing Office No

2 Novotny TE, Romano RA, Davis RM, Mills ST. The public health practice of tobacco control: lessor learned and directions for the states in the 1990s. An Rev Public Health 1992;13:287-318. 3 Davis R. Tobacco policy research comes
Control 1995;4:6-9.

4 Songer DR, Underwood JM, Dillon SG, Jar@eson PE, Kite DW. Voting cues in two state legislatures: a further application of the Kingdon model. Soc Sci $\$ 1985 ; 66: 983-$ 90 .

5 Stratmann $T$. What do campaign contritioutions buy? Deciphering causal effects of money and Astes. Southern Econ F 199 1;57:606-20.

6 Jones Jr. W, Keiser KR. US senate voting hon health and safety regulation: the effects of ideology an hiterest-group orientations. Health Policy 1986;6:33-44. $\omega$

7 Wright JR. PACs, contributions and roll calts. an organizational perspective. Am Polit Sci Rev 1985;7\%400-14.

8 Wright JR. Contributions, lobbying, and cofmittee voting in the US House of Representatives. An Polit Sci Rev 1990;84:417-38.

1990;84:417-38. Samuels B, Glantz SA. The politics of local tobacco control. FAMA 1991;266:2110-7.

10 Jacobson PD, Wasserman J, Raube K. The politics of antismoking legislation. $f$ Health Polit Po 18:787-819

11 Glantz SA, Begay ME. Tobacco indu蓆y campaign contributions are affecting tobacco controfpolicymaking in California. $\mathscr{f} A M A$ 1994;272:1175-82.

12 Moore S, Wolfe SM, Lindes D, Douglas CE Epidemiology of failed tobacco control legislation. OAMA 1994; 272:1171-5.

13 Goldstein AO, Cohen JE, Flynn BS, et al. S吾te legislators' attitudes and voting intentions about tobeco control leattitudes and voting intentions about tobace cont
gislation. Am f Public Health 1997;87:1197:-200.

14 Stata Corporation. Stata reference manual: release 5. Vol. 1. College Station, Texas: Stata Corporation, 1997.

15 Goldstein AO, Bearman NS. Epidemiology of state tobacco lobbyists and organizations in the United States. $A m \mathcal{F}$ Public Health 1996;86:1137-42. 
16 Carney JK, Hamrell MC, Wargo WE No butts about it: public smoking ends in Vermont. Am f Public Health 1997;

17 Todd JS, Rennie D, McAfee RE, et al. The Brown and Williamson documents. Where do we go from here? $7 A M A$ $1995 ; 274: 256-8$
18 The smoke hasn't cleared. American Medical News 1996 Oct 14:17.

19 Flynn BS, Dana GS, Goldstein AO, et al. State legislators' $\vec{O}$ intentions to vote and subsequent votes on tobacco control legislation. Health Psychol 1997;16:401-4.

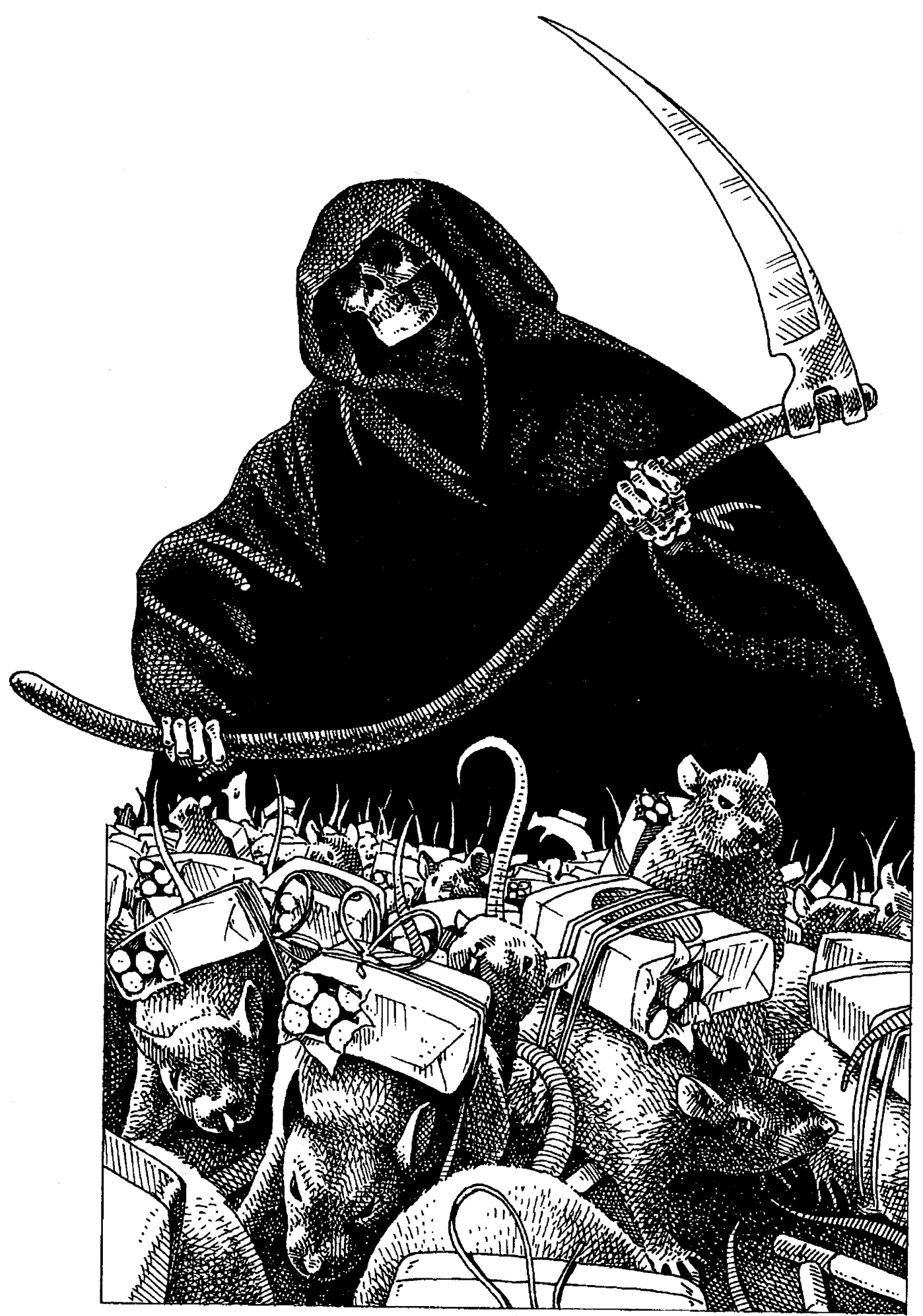

